\title{
1 Region as a small open economy and an exporter
}

\subsection{Region as "something in between"}

Our approach to the analysis of exports and imports is not common in literature, as most of the research is performed at country or sectoral level. The theories and concepts applied to the analysis of international trade as such, have been created for the trading countries, not regions. Therefore, for an economist, it is challenging to make a serious inquiry into the nature of regions' foreign trade activity, based on the solid theoretical background. The solution is treating the region as a small open economy (SOE), which enables the transposition of most of the international economics apparatus into the regions' world.

In the literature, a region understood as an SOE is treated as "something in between” (Eswaran, Kotwal, Ramaswami, and Wadhwa, 2007; Siebert, 1969), an intermediate category, situated between an aggregated economy (in which the spatial dimension does not exist) and highly disaggregated system, understood as a set of places in space. The conceptual approach proposed by Siebert (also represented by Cassey (2011b)) enables to choose the most appropriate level for aggregation of statistical data for economic entities (firms). The proper level of data aggregation is essential, for instance, in the analysis of intra-industry trade (IIT). If a highly disaggregated product classification level is used, accompanied by low-level territorial units - unnaturally low values of IIT indices could be expected (Umiński, 2014; Yoshida, 2008). It sheds appealing light on the problems with transposition of international economics apparatus to the regional level of analysis. Siebert (1969) noticed that in the classical economic models, the deductive process was based on the prerequisite of a one-point economy, having no spatial dimension. Therefore, the main questions, such as how to produce, who produces, who is the consumer - were interpreted in a non-spatial, distanceless world, with non-existent transport costs.

\subsection{International trade theories - they are changing}

Several essential prerequisites can be exemplified, once we look for relevant theoretical concepts explaining regions' participation in international trade:

(a) international trade theories have been changing. Besides concepts strictly related to trading countries (i.e. $\mathrm{H}-\mathrm{O}$ theorem), far more universal apparatus has been applied, such as the gravity model, 
(b) undoubtedly a question can be formulated how far this universalism reaches. According to Cieślik (2005) and Findlay (1995), there appears an integrated general theory of localisation, relative factors endowment and international trade in conditions of increasing returns to scale - which is composed of new economic geography (NEG) and the international trade theory. NEG evolves in the micro-heterogeneity direction, thus incorporating the firm's heterogeneity in productivity, a crucial element in contemporary research on international trade. However, NEG has been severely criticised by geographers, for whom many aspects of NEG cannot be accepted because of the high contextuality of regional analysis,

(c) also, some elements of international economics seem to have become less critical. For instance, there is no need to bother so much with foreign currency exchange issues, while analysing trade within the currency union, such as the eurozone. It simplifies the regions' foreign trade analysis, as the number of trade determinants can be reduced,

(d) another question is to what extent does international trade resembles interregional trade, once it happens within the internal market of the EU (in the eurozone in particular), with no trade obstacles,

(e) the fundamental question, however, is how seriously we treat assumptions present in international trade theories. A vivid example is $\mathrm{H}-\mathrm{O}$ theorem, in which strict assumptions have been formulated related to differences between trading partners resulting from differences in factors endowment and factors' mobility. Shall countries be treated as flat (Krugman, 2015) or lumpy (Courant and Deardorff, 1992)?

Acknowledging that in empirical studies, we observe acute differentiation of regions' export profiles is a substantial prerequisite for further considerations and search for theories that can be applied to regions' participation in foreign trade. Those differences inspire us to use the international trade apparatus, theories and models to interpret a region's exports. Yet, many concepts originated from international trade theory have much broader, universal application, a perfect example being the comparative advantage rule that is widely used in regions' competitiveness assessments. A permeation of regional and international economics is a fact.

Our intention is not to provide the reader with the fully-fledged, comprehensive inquiry into the theory of international trade applied to regions. We instead focus on the selected, most interesting theoretical concepts, which in our opinion, clarify of the nexus between the region and the global economy. These are mercantilism, absolute and comparative advantages within the standard model of international trade, factor endowment within $\mathrm{H}-\mathrm{O}$ theorem, IIT, demand-side related theories, FDI and concepts incorporating technological dimension. NEG is only briefly mentioned, as it is described in a detailed way in section 2.3. Also, the gravity model is not discussed because it is presented in section 8 . 


\subsection{Mercantilism - an almost forgotten, but useful concept}

This old, almost forgotten concept that has been the solid background for the economic and foreign trade policy between the early $16^{\text {th }}$ and the mid-18 ${ }^{\text {th }}$ centuries still seems useful for regions, as SOEs, participating in the global market (Landreth, Szeworski, Godłów-Legiędź, Dzionek-Kozłowska, and Colander, 2013). The fully-fledged application of the concept of mercantilism to regional analysis is difficult because its important component are monetary issues - and monetary policy as such is not performed at the regional level. Mercantilism postulated positive trade balance, available also through active foreign trade policy. Such policy is obviously not conducted at the regional level, as it belongs to the exclusive competences of the EU. Regions are, however, not wholly deprived of the possibilities to influence their trade balance, which is often perceived as a primary indicator of competitiveness. As mentioned, the promotion of exports is often transposed to regional agencies/institutions, and their aim is explicitly defined as improvements in competitiveness, regions' foreign trade balance, and - generally - the promotion of export base and regional exporters (see sections 11 and 12, where policy-related issues are undertaken). A similar approach may be adapted to regions competing over the EU structural and investment funds or export subsidies. Promotion of a region's exports is perceived as a tool to increase employment. If a region hosts a substantial number of firms which are the key players in a particular sector of the economy and their market position is threatened by foreign competitors, these firms may postulate the introduction of antidumping or anti-subsidy procedures. In that way, a region - or a group of regions having similar production or trade profile (in section 7.7 regions are grouped into clusters, comprising similar units in terms of exports) - can influence the EU common commercial policy. Summing up, mercantilism, although not perfectly suited for analysing trade of regions, is an interesting concept, suitable for understanding the regions' participation in world trade.

\subsection{Standard model of international trade}

Within the standard model of international trade, two approaches can be identified, which are the absolute or comparative advantages. Both theories, formulated by A. Smith and D. Ricardo respectively, are well described in the literature; therefore there is no need to elaborate on their assumptions and predictions (Batabyal and Nijkamp, 2015, p. 4). In fact, they have become the most important concepts in economics. Both are used in the discussion related to how regions' competitiveness shall be perceived. The comparative advantage rule, applied to regions, brings an important and optimistic conclusion that although a region may not have any absolute advantages due to high costs of production or low productivity, there are products in which the comparative advantage can be found, making foreign trade beneficial. As mentioned by 
Batabyal and Nijkamp (2015, p. 4), the main drawback of the Ricardian concept is that in the model trade does not affect the distribution of income, which in the real world produces clear winners and losers.

The comparative advantage rule has its important practical and empirical application, which is the variety of measures, such as revealed comparative advantages or location quotients indices, intensively used in the assessments of competitiveness (see section 7 for an empirical application). In both - absolute and comparative advantage - the benefits from trade are shown as an equilibrium in an open economy (with trade) compared with an equilibrium in the state of autarky. In the model, there is a state of autarky, which is a problematic issue because, in the real world, it is hard to find a country representing a closed economy. Regional economies are "closer" to the autarkical state, primarily if a region's economy is dominated by an industrial sector characterised by low export intensity. In other words, it is easier to find an almost autarkical region, than a country, especially if the analysis is performed at a low level of regions' delimitation. In this respect, section 6 deals with rational trade openness, while in section 7 , differences in exports per capita are addressed.

\subsection{Factor endowment}

According to the Heckscher-Ohlin (H-O) paradigm (applied to regions), it is highly probable that a region relatively well abounded with labour will specialise in production and exporting of labour-intensive goods and will import goods that require intensive use of the scarce (and relatively expensive) factor. Another region will specialise in production and export of capital-intensive goods. It is a simple transposition of the $\mathrm{H}-\mathrm{O}$ theory to the situations of regions engaged in international trade. Factor endowment constitutes a source of competitiveness that enables the region to benefit from international trade and the division of labour and capital. The H-O theory was extended to include not only capital and labour, but also differentiated factors (such as qualified and unqualified labour).

$\mathrm{H}-\mathrm{O}$ theorem is rigorous in its assumptions. One of them is the factors' immobility: they are only mobile, as being embodied within the products being traded. It is problematic in the analysis focused on regions. In reality, factors do migrate between regions and the more mobile they are, the less region's foreign trade is determined by its indigenous factors' abundance. This problem is signalled by Krugman (2015), who points to the narrowing factor-price differences, which reduces the reason to trade. Whether the countries are flat or differentiated (lumpy) - it will remain the question of the debate. According to Krugman (2015, p. 29), the world cannot be regarded as flat, but America - due to the high mobility of ideas, people and capital - can. The alternative point of view was presented by Armington (1969), according to whom customers differentiate the products by their attributes, which are specific to the place of origin. In other words: a customer pays attention if, for instance, wine comes from 
the Chianti region, or from other regions, which stops the world from becoming flat. Products traded are not "the same".

$\mathrm{H}-\mathrm{O}$ theory rests on the assumption that trading partners are different; the essential difference is related to factor endowment. There are two possible approaches on how to perceive those differences, which undoubtedly is a rather casual interpretation of the basic $\mathrm{H}-\mathrm{O}$ theorem: (i) a region can be compared to other regions within a country, participating in international trade; (ii) or it can be compared to the "rest of the world", which obviously would require the much more comprehensive and large dataset to be included in the analysis. In fact, flexible approaches can be found in empirical research, $\mathrm{H}-\mathrm{O}$ being one of the most important conceptual frameworks, constituting the fundament of international trade analysis.

The question is, how useful is H-O theory for the analysis of contemporary foreign trade, in which trade shifts towards more similar ("less different") trading partners. It implies that other theories will gain importance, for instance, IIT conception. Still, for Poland and Spain, H-O theorem holds its usefulness for the interpretation of trading partners with countries that are different in terms of the level of development etc.

The so-called missing trade problem shall be mentioned, as often trade intensity between partners turns out to be less intensive than predicted by $\mathrm{H}-\mathrm{O}$ theory-based models. The missing trade problem is one of the reasons for the gravity concept (see section 8 for an empirical example of its use) to become useful in trade interpretations (Brodzicki and Umiński, 2017), as it focuses on the explanation of factors that hamper trade.

Courant and Deardorff (1992) formulated a lumpy country concept, which introduces regional differences to the initial H-O model. Each of the country's regions can specialise in exports and imports of different products, which implies that factors' proportions do not necessary equalise. It has an important consequence: regions' trade specialisation can be idiosyncratic. If a nation's foreign trade is dominated by a few regions, it is very likely that the structure of their trade is similar to that of the whole country. The remaining regions (having lower shares in the nation's trade) can reveal significant idiosyncrasies in their trade characteristics. According to Courant and Deardorff (1992), a nation's foreign trade in which factors are equally distributed among its regions will be different to a situation, in which there are significant inequalities among regions in terms of their factors endowment. The main conclusion formulated by Courant and Deardorff (1992) is that regional inequality in factor endowment determines a nation's foreign trade. Thus, regional inequalities shall be considered. Ceteris paribus, a nation tends to export a good, production of which requires more intensive use of the factor, which is lumpier (more unevenly distributed). If differences in factors endowment are large, regions may reveal complete specialisation (in one product), which rarely happens at a country level. A paper by Courant and Deardorff (1992) shall be perceived as a serious invitation to treat regions as SOEs that have their own distinct factors endowment and therefore reveal specific trade patterns. 
The H-O model was also complemented by a group of neo-technological theories, in which the importance of technological differences was highlighted. Schumpeter (2013) and Marshall (1919) investigated the relationship between technological advancement and international trade. First, the interdependence of innovation, imitating technological progress and foreign trade was emphasised. Marshall focused on methods of technology transfer between countries and their impact on comparative advantage. Based on these considerations, Posner (1961) formulated the outline of the technology gap theory, explaining the way in which technological progress and technology transfer affect the development of international trade.

Hufbauer (1970) (1966) and Krugman (1979) contributed to the theory stating that different levels of specific knowledge and technology advancement ("ladder of countries"), as well as limited possibilities of fast and free access to technical knowledge from other countries, are responsible for observing international trade. Regions can be ranked according to their technological development: the higher the level of technological development, the higher the products are at the scale of production capacity, which is also the scale of comparative advantage. In Rethinking International Trade (Krugman, 1990), pointed to the process of "closing of the gap", that is to decreasing superiority of industrial nations. The set of neo-technological theories is often referred to when analysing trade flows of regions. They may be applied to regions that can be ranked on a "technological advancement ladder". The differences in the technological advancement of production might be observed between regions, constituting the base of competitive advantages.

\subsection{Intra-industry trade}

IIT explains the overlap between exports and imports, while differentiated products from the same product group are traded, being close substitutes in production or consumption. IIT is a type of trade that happens predominantly between "similar" countries, in terms of their level of development, in which customers demand "variety". The "love for variety" is a factor that stimulates the growing role of IIT. Product differentiation (heterogeneity), economies of scale and imperfect competition are traditionally regarded as factors constituting the base for IIT. However, in the more upto-date literature, production fragmentation between countries has been identified as a factor that intensifies IIT (ABS, 2019a; Cieślik, 2008; Krugman, 1979; Marrewijk, 2008; OECD, 2002; Yoshida, 2008, 2008), which stems from FDI (mostly MNEs) activity (Cieślik, 2008). Two main types of IIT can be distinguished: horizontal (goods are differentiated by attributes) and vertical (goods are differentiated by quality). The distinction between the two types of IIT is made with the use of unit value criterion (Krugman, 1979; Greenaway, Hine, and Milner, 1995). IIT theory was formulated for countries. Therefore, benefits stemming from it traditionally were discussed for 
country-level of analysis. As regards regions, the gains from IIT were not particularly reviewed yet, and they undoubtedly deserve attention and more profound research.

With respect to IIT analysis for regions, the following issues shall be considered:

1. At the regional level, high intensity of IIT reflects not so much "love for variety", but production fragmentation, often driven by FOEs activity. If IIT is a result of FDI, then all the possible consequences of FDI inflow disclose in the regional economy. They are positive and negative, as FOEs are "multidimensional creatures" (Forsgren, 2008).

2. FOEs often co-localise, which draws our attention to agglomeration processes. If agglomeration embraces firms from the same industry, it increases vulnerability, because the regional economy becomes more specialised. On the contrary, "differentiated" agglomeration (embracing firms from different industries) may decrease vulnerability.

3. IIT is driven by economies of scale, which as such are positive, as they constitute a base for trade. However, ceteris paribus, they make the regional economy more specialised, which - again - increases vulnerability.

4. Agglomeration and specialisation lead to new resources being attracted to the region, incl. human resources. It changes regions' position against other regions.

5. IIT is more intense between spatially closer trading partners. Due to cumulative causation, proximity contributes to furtherly intensified trade relations (that is what gravity teaches us), as trade costs matter.

6. Due to IIT, a region's positioning on a trade quality ladder is settled. It depends on the type of IIT, whether it is horizontal or vertical (low quality/down market or the high quality/high market).

7. Intensive IIT takes place in relations among integrated partners, which eliminated trade barriers. It reduces the likelihood for a regional economy to be hit by an unanticipated implementation of trade barriers. It positively contributes to economic stability in the region.

After an extensive overview of theoretical IIT underpinnings, Brodzicki (2016b) concludes that the structure of IIT and its directions are highly unpredictable. The question why the particular region is engaged in the IIT is even more difficult to answer. Regions are different, and their foreign trade profiles are different, described by geographical, product patterns, trade intensity per capita etc. Regions' IIT overall intensity inequalities, may stem from specific IIT intensity of particular products groups. However, concrete outcome results from a combination of industry-specific and regional-specific factors. Different IIT intensity of regions' trade may reflect industry branches' specific capability to generate IIT. Some industries generate higher IIT, in others IIT intensity is lower, or even $\mathrm{H}-\mathrm{O}$ type of trade dominates. 


\subsection{Demand-side related theories}

In the standard model of international trade, demand-side of the market is ("sooner or later") introduced. Offer curves (or reciprocal supply/demand curves) illustrate market equilibrium: the quantity offered and demanded by trade partners. If regions are treated as SOEs, reciprocal demand curves could have some usefulness. Originating from international economics literature, they draw our attention to the question of demand. If for instance, indifference maps can be created not only for an individual customer but also for nations (as it is done in international economics literature), they could also be constructed for regions.

Linder's (Linder, 1961) concept of preference similarity is used in international economics as a useful instrument for interpretations of trade in industrial goods. It does not pretend to be a comprehensive theory of international trade, because it, in fact, ignores the supply side of the market, therefore depressing the significance of factor endowment. The main prediction of the Linder (1961) model is that in countries with a similar demand, the same (or similar) industries will develop. The so-called representative demand appears, and it stimulates trade between countries. Producers seek the market, in which they can satisfy demand, which resembles the one they know from their domestic market. Therefore, the similarity in the structure of demand positively contributes to trade intensity. GDP per capita was suggested by BurenstamLinder as a proxy of demand preference similarity. If markets are similar, the socalled transfer costs associated with expansion to these markets can be reduced (for instance, the scope of necessary products' adaptation is lower).

Brodzicki and Umiński (2017) indicate that preferences similarity concept in region-country framework is related to gravity. The distance between the trading partners shall, therefore, be understood more broadly. Not only in terms of distance stemming from the structure of demand but also in terms of many other factors that reduce demand (i.e. cultural, linguistic, institutional, legal differences, etc.). According to the gravity concept used in international economics, they all can be responsible for "missing trade".

Among demand-related theories, also Armington (1969) type preferences shall be mentioned (already presented in the section on factor endowment).

\subsection{Region as small open economy interpretations}

The region as an SOE concept has also been used for interpretations of the relation between the regional and the world economy by Llop and Manresa (2007), focused on exports and foreign trade multiplier for Catalonia. The study of the Karela region in India (Harilal and Joseph, 2003) proves that any analysis must take into account that a region is a part of a world economy and is subject to its rules. Also, for India, Barua and Sawhney (2015) conclude that more impoverished regions gained in 
income growth from greater openness; however, the gains were not significant enough to offset the increasing regional disparities. For the Catalan economy, (Llop and Manresa, 2007) pay attention to multiplier effects, including the foreign-oriented sector of the regional economy.

The SOE concept of a region supplements various spheres, through which a region can be perceived, which according to Tomaszewski (2007) are: legal, geographic, economic, societal, ethnic and politological. These spheres affect the way in which a region functions within the global economy. The econometric models that search for countries' and regions' foreign trade determinants (Kepaptsoglou, Karlaftis, and Tsamboulas, 2010) prove how many factors exert an effect on the intensity and patterns of trade relations, including specific variables from the spheres listed by Tomaszewski (2007). However, Tomaszewski (2007) does not mention the role of region as an exporter. The concept of a region as an exporter is rarely mentioned in the literature in an explicit way. It has, however, been noticed by Florida (1995) that the most important linkages of regions are the ones with the global economy - not with host nations. According to Florida (1995), regions create effective points of entry into the global economy, and their characteristics differ. Domański (2013) underlines that each region has its individual, economic profile. The concept of a profile accommodates a wide variety of structural characteristics that in an empirical way are used to make the assessments of regions' competitiveness, investment attractiveness or any other inquiries, including the analysis of foreign trade relations.

The administrative sphere in which a region is placed shall be recalled here. According to Głąbicka and Grewiński (2005), a region is defined as an inseparable part, in cultural, societal and economic spheres. However, this administrative division may not have been done optimally, meaning that some parts of a region may have traditionally been strongly linked to the neighbouring regions. This problem has also been presented by Krugman and Venables (1995) with reference to the seamless world concept, in which international spatial specialisation evolves in a natural way.

Umiński (2012) distinguishes two main aspects of a region's participation in the international economic processes. In the first one, a region is perceived as being dependent on the international processes, such as exports, imports, capital transfers, migration of people. A region is thus a recipient of processes occurring in the international environment. The changes in the business cycles trends, economic and technological shocks affect the regional economy. These changes are finally reflected in the situation on the regional labour market; however, these are also within-regional factors that influence the labour market trends. In the second one, a region is perceived as able to influence the international markets, which obviously is an attribute of competitive, core regions from competitive countries. They are hosts for transnational corporations and are the source of lobbying that influences other economic agents. If such a region hosts large importers, their monopsonist position may affect the demand on the world market and the prices thereof. 
A region can influence the international economic environment, especially if its size is relatively big. In the particular segments of the market or niche products, this influence can be substantial, even if a region's size is not that big. That is a case of highly specialised exporting firms, located for instance in the coastal areas, producing maritime transport equipment.

Referring to foreign trade policy, enterprises from such a strong region may initialise the antidumping procedures or disseminate new technologies or innovative solutions. Umiński (2012) concludes that each economic process does not take place in an undefined space, but rather in concrete locations. Interpreting it in the context of international economics, a transaction that is registered as the one occurring between countries occurs between specific places (or regions). It occurs between firms (economic agents), located in particular locations, performing various functions, which makes it difficult to unequivocally determine where the "export journey" begins. It can be the place in which the product has been manufactured, or substantially modified; or a place from which the shipment to foreign market begins; or alternatively a place in which the decision-making functions are performed, decisive for a firm's ability to export (Brodzicki and Umiński, 2017; Coughlin and Mandelbaum, 1991; Coughlin and Pollard, 2001; Coughlin and Wall, 2003; US Department of Commerce, 2013).

\subsection{Heterogeneity of regions and firms}

As already noticed, the role of a region as an exporter is relatively new. It has developed and strengthened with the increasing globalisation, deeply embracing various aspects of the regions' economies. Regions' heterogeneity thus gained a new dimension, so far neglected, which is the sphere of foreign trade. The recognition of this heterogeneity resulted in a spectrum of possible studies that, with the use of the international economics apparatus, assess the export performance of regions. Those inquiries are a part of the regional competitiveness assessments. However, also more focused and in-depth analysis is possible, for instance, related to the IIT. In section 7, we present selected aspects of this heterogeneity, referring to the structural characteristics of Poland's and Spain's NUTS 2 regions as well as the observed trends thereof.

The increasing globalisation has revealed the uneven competitiveness of regions. The highly competitive ones, hosting the most dynamic and productive firms, are those predesignated to get the most benefits from functioning within the open economy. It means that globalisation may increase already existing inequalities in regional development. Much depends, however, on the firms' and regions' characteristics. According to the heterogeneity concept by Melitz (2003), only the most productive firms become exporters; both theoretical and empirical literature shows a widespread consensus on it. It has been expected that the learning by exporting effect also exists, meaning that once a firm becomes an exporter, its productivity increases further - but 
it has not been proved in most of the research conducted. At the regional level of the inquiry, other mechanisms can be identified that increase regional inequality. Firms tend to agglomerate, meaning that the presence of an exporting firm in the region attracts other firms, including exporters. This effect has been well documented in the theoretical literature within NEG and NNEG. Exporters tend to agglomerate because of the learning, sharing and matching effects. They reduce the costs associated with exporting as well as decrease the risk of expansion on foreign markets. Baldwin and Okubo (2006) have identified the sorting and selecting effects. Accordingly, the most productive firms locate in the most competitive regions, which - as already mentioned - increases the already existent regional inequalities.

According to Florida (1995, p. 531), regions "can be distinguished by the level and extent of their insertion in the international economy and by their willingness to participate in global trade". While it is generally acknowledged that presence of exporting firms in a region brings positive consequences and proves a region's high competitiveness (understood as an ability to sell and to export), the question can be asked if there is a maximum level of openness, that can be regarded as "safe" for the region's economy. In fact, openness brings both positive and negative effects. Too much openness may cause instability and may result in the volatility in the economic situation of the region (Baldwin and Brown, 2004; Brodzicki, 2017b; Coulombe, 2007; Cronovich and Gazel, 1998; Hirose and Yoshida, 2018; Leichenko and Silva, 2004; Paluzie, Pons, and Tirado, 2001; Rodríguez-Pose, Tselios, Winkler, and Farole, 2013).

These negative consequences usually stem from a crisis (such as the one from 2008 and the following years) and from the strategies of the multinational enterprises, whose production relocations processes influence regions' economy in a severe way. For instance, for southern areas of Poland (Śląskie and Dolnośląskie), heavily dependent on exports on the FOEs' activity (predominantly in the automobile industry), the 2008 crisis has revealed the necessity to diversify the structure of production and exports, in terms of structural and geographical patterns, and also in terms of ownership. The question if openness brings stability or rather volatility to the regional economy, and its labour market, in particular, is also frequently asked by the authorities responsible for regional development policy.

There are several interesting aspects of the regions' heterogeneity that shall be mentioned. For instance, changes in the foreign trade policy instruments (incl. alterations in customs tariffs) and effective protection have a heterogeneous effect on regions, once their export and import structures differ. Fluctuations of the exchange rate of a national currency vs EUR or USD (Poland is not a member of the eurozone) are expected to have heterogeneous effects on regions' situations, depending on their export and import geographical structure and - which is most important - trade balance.

Once regions function in an open economy and the scope of their openness differs, any economic shock that happens in the global markets is likely to exert heterogeneous effects on regions' economies. Given regions' different structures of 
production, innovativeness capacity, productivity, product and geographical structure of exports as well as its technological advancement, regions display heterogeneous sensitivity to globalisation (OIR, 2011). The 2008 crisis and its consequences have clearly shown the pros and cons for regions of being strongly linked to global markets. Regions' competitiveness differs. Adaptive capacity is essential since it facilitates adjustments of regional economies to the changing global situation and the alterations stemming from the activity of MNEs.

Factors that influence regions' economic situation not only belong to the sphere of economics but also politics. The global situation has become highly unpredictable and uncertain. Shift of the position of the of US vs. China as the leading power in the global economy, the increasing competitiveness of the Indian economy, the uncertainty about the future of the integration processes within the European Union and the consequences of Brexit (if it will materialise at all), trade wars (that prove the rebirth of protectionism) and possible currency wars, a shift from multilateralism to bilateralism in global trade and investment arrangements - are the main factors contributing to the increasing uncertainty that already has and will have effects on regions' open economies. It makes a region's economies adaptive capacity an important category that facilitates structural adjustments to shocks and mitigates the consequences of sensitivity and vulnerability.

\subsection{The principle of subsidiarity}

An interesting perspective and theoretical background for the analysis of exports at the regional level is provided by the principle of subsidiarity, which became a part of the EU's acquis communautaire. In its profound meaning, it relates to the delegation of decision-making rights, which can also be used in the interpretations of exports and exports promotion in particular. According to Delsol (1993), subsidiarity refers to socio-political order, in which competences or prerogatives are preliminarily assigned to the social actors. Only if they turn to be inefficient or ineffective, the necessary action shall be taken by higher-level agents/institutions. These can be regional or national bodies. Once they prove to be ineffective, the EU level involvement can be justified. It is an example of the down-top transfer of competences. In the case of exports, we rather think of a top-down approach, in which for instance, promotion of exports - traditionally performed at country level - is transposed to regional agents. According to the principle of subsidiarity, exports promotion at the regional level can be more productive. Agency/institution responsible for promotion is "closer" to the firms, which need assistance. Therefore, their needs can be better inquired and assisted. According to the UE legislation, commercial policy belongs to the exclusive competences domain of the EU's institutions; however, the export promotion rules have not been harmonised in practice, and member states (MS) have much freedom in 
the way how intensively and in which form exports is promoted, at country or region level.

Subsidiarity is often understood as a tool to improve social structures and procedures. Practically, what matters in the light of our divagations is the effectiveness of exports promotion. Any existing bottlenecks in a region's exports can more easily be identified by a regional promotion agency, which is "closer" to the problems of local firms. Regional vs national promotional agents/agencies could have different priorities regarding exports promotion. A region could reveal a particular pattern of export links. For instance, Pomorskie region in Poland shows intensive trade relations with non-EU countries, many of which represent relatively small markets, from the perspective of the whole country's trade relations. However, Pomorskie has revealed distinctive comparative advantages, which from the perspective of the region's exporters, shall be promoted and strengthened.

Moreover, the promotion of a region's exports needs to be a part of a broader, regional, general economic policy scheme, of which smart specialisation and regional innovation strategies are the key elements (section 12 deals with the issue of smart specialisation). As stems from the firms' heterogeneity concept, well documented in the theoretical and empirical research, there is a clear nexus between innovativeness, productivity and export performance. However, it is not clearly reflected in smart specialisation strategies.

The subsidiarity principle assumes that the problems shall be solved as close to the citizen as possible. Translating it to the exporting activity, decision and actions shall be taken as closely as possible to the level that they apply to. It also relates to the promotion of a region as an attractive place for FDI. FOEs are expected to benefit from the advantages possessed by the foreign owner, which often represents the MNE. It is generally acknowledged in the literature that FOEs have higher productivity, compared to indigenous firms, which translates into higher exports (Helpman, Melitz, and Yeaple, 2004).

\subsection{Foreign direct investment}

Openness has many faces. Several channels can be listed through which the impulses from the global economy are transmitted to the regional one. These are foreign trade, migrations, technology transfer and last but not least global value chains (Abreu, Groot, \& Florax, 2004; Bentivogli, Ferraresi, Monti, Paniccià, and Rosignoli, 2018). Processes occurring within each of these channels are highly interrelated. The literature relevant to analyse each of the channels is enormous, allowing thorough interpretations, especially if one applies the SOE concept.

A critical channel is FDI. FOEs contribution to exports varies among countries and their regions. Their share in particular regions' exports can be very high. The inflow of FDI, and FOEs activity thereof, significantly determines the dynamics of many 
regions' exports and imports, as well as their product and geographical patterns. The inclusion of FDI theory in the analysis of a region's foreign trade activity seems crucial. Processes observed in a region's trade often turn out to be better explainable and understood, if FDI-related theories are used, and statistical data on FDI's role is included on the list of the independent variables. FOEs' crucial role in trade is especially visible in transition or post-transition countries, in which economic growth and transition process have been financed, to a large extent, from foreign savings.

Mayer and Ottaviano (2008) show FOEs' higher inclination to engage in international transactions vs domestic firms. Through externalities, FOEs exert influence on indigenous firms, also positively contributing to their performance (although a negative impact can also occur). The multidimensional character of FOEs shall be recollected, which is essential in the formulation of expectations and conclusions related to FDI presence in regions' economies. Forsgren (2008) describes the multinational firm as a "beauty and a beast", stating that there are many conflicting views on its nature. He defines the functions that can be assigned to multinational firms. They are dominators, having serious market power. They also perform the coordination role, with a focus on cost efficiency, possible through internalisation. Multinationals can be regarded as knowing firms, taking part in the knowledge creation and exchange process. They also serve as designers and networkers, engaged in creating business networks. Multinationals also perform a politicising role.

According to the classical view on FDI by Dunning and Lundan (2008), FOEs possess ownership advantages, which is one of the components of the OLI paradigm (Ownership, Location and Internalisation). The ownership-specific advantage stems not only from tangible assets as capital, natural resources endowment or workforce. It also embraces a package of intangibles, such as technological capabilities, marketing and managerial skills and favourable access to intermediate goods. Also, another component of the OLI paradigm deserves attention, which is internalisation, which usually embraces economic activity dispersed among many parts of the MNE, localised in various nations (production fragmentation). It contributes to a region's IIT, as already mentioned.

Although it was stated that at a regional level, the significant positive inflow of FOEs on exports and imports is identified, the nexus between FDI and trade, in theory, is not that obvious. Complementarity or substitution between trade and FDI is frequently discussed in the literature. If the purpose of FDI is to "jump" over tariffs, the indigenous market of the country in which investment was made is the target, and FDI substitutes trade (Blomström, Globerman, and Kokko, 2002). On the other hand, Helpman (1984) and Helpman, E. and Krugman, P. R. (1985) predict FDI to be complementary to trade if there are significant differences between countries in terms of factors endowment. FOEs make use of their ability to internalise the market and draw benefit from different locations' advantages. For instance, labour-intensive activity (part of the value-added creation chain) is located in labour abounded countries/ 
regions, capital intensive in capital ones, etc. It creates trade (IIT in particular), as the final product embraces components coming from many locations.

In proximity-concentration models, firms invest abroad in order to avoid trade costs. From the fact of being close to the market, that is served, proximity benefits occur. This results in the establishment of FDIs. On the other hand, avoidance of duplicating fixed costs (associated with plants located in many countries), encourages a firm to concentrate production in one (or in few) countries/locations. Concentration benefits arise, which creates exports; however, FDI is not done (or is done at a smaller scale). Therefore, if concentration advantages dominate over proximity advantages, trade substitutes FDI (Brainard, S., Lael, 1993; Markusen, 1984).

Also, the motives of investment done in foreign markets matter. FOEs can be looking for the resources, market efficiency or strategic assets and capabilities (Behrman, Jack, N., 1972; Dunning and Lundan, 2008; Iammarino and McCann, 2013; Jensen, 2002). The consequence of the different motives driving foreign investment activity can be that even if an investor possesses ownership advantages, they do not necessarily translate into higher exports.

From the point of view of research on the region's exports nature, the character and the size of the export premium that FOEs have over non-FOEs - matters. The premium can be measured, for instance, as the propensity to export (the likelihood that a firm becomes an exporter), export intensity (exports share in total sales) or, for instance, the intensity of IIT. A FOE can rely on its ownership advantages that it possesses over the indigenous companies in a host country. They manifest in higher productivity (Antras and Yeaple, 2014), which, according to heterogeneity theory, increases the probability of exporting. As regards export intensity, the influence of foreign ownership has not been clearly identified empirically. Dunning and Lundan (2008, pp. 493-495) performed an extensive inquiry of the empirical research on the differences between FOEs and their indigenous counterparts, regarding export intensity, covering publications for the period 1958-2006, for both developing and developed countries. Accordingly, definite conclusions cannot be formulated due to the methodological differences between the studies inquired. Much depends on the combination of particular motives that drive FOE's activity and the structure of the given OLI (Dunning and Lundan, 2008; Estrin, Meyer, Wright, and Foliano, 2008; Forsgren, 2008).

\subsection{FDI early theories reinterpreted}

Stephen Hymer's (1960/1976) doctoral dissertation is regarded as a pioneering contribution to the theory of FDI. It showed the differences between portfolio and direct foreign investment, by focusing on the specific ownership advantages, possessed by a multinational firm. It is Hymer, who pointed out that FDI is not only capital being 
transferred through investment done in another country, but a group of resources, including entrepreneurship, technology, marketing, skills etc.

The thorough interpretation of Hymer's contribution to the understanding of location choices was provided by Iammarino and McCann (2013). According to Hymer's law of increasing firm size, as the company develops and transforms into the multinational enterprise, a pyramidal structure evolves, with three different levels of hierarchy. The lowest level is production; the higher one is an intermediary, performing control and coordination. The highest one performs top-level management and makes strategic decisions. According to the "correspondence principle", the hierarchical structure of multinational enterprise translates into the hierarchy of locations (Iammarino and McCann, 2013). The highest level of the hierarchy is located in global cities. The lowest one remains relatively evenly spread among locations, reflecting their attractiveness (described by resources offered, like labour, raw materials, etc.). The intermediary level is clustered around big cities, providing sufficient communication networks and qualified labour (Hymer, 1972).

Hymer's "correspondence principle" shows that FOEs activity contributes to uneven regional development. By "assigning" different roles to the locations, the interesting interplay between industrial and regional structures is developed by the FOEs. One of these roles is production, dedicated to export markets, making a particular location an exporter.

Another "early" theory of multinational enterprises that can be useful in the analysis of a region's exports is the product life cycle (PLC) by Richard Vernon. It shall be reviewed jointly with the comparative advantage concept (applied to regions). The PLC (Vernon, 1966) is one of the main concepts used in international economics. Referring to the microeconomic perspective, acknowledging market imperfections, Vernon sees innovation-related advantages as a result of technological gaps. At each of the stages of the life cycle that a product "passes" through, specific assets are needed. For instance, when an innovative product is born, it is sold on the domestic market, offering high demand, large enough to cover high production costs associated with risky, innovative production. Production is not yet performed at a larger scale that would enable economies of scale to occur. When exports arise, products are directed to similar countries, representing comparable demand conditions. In the second stage, FDI is done with the purpose to serve the local markets directly. In the standardisation stage, production is moved to low labour costs countries, and the home market is supplied through imports. PLC theory links multinational enterprise activity with particular locations through a hierarchy of requirements stemming from the ownership advantages. For instance, in the first stage of the PLC, production is performed in locations that are metropolises in the most developed countries. Innovations are generated in such places. A variety of available resources (mainly human capital and the required business services) in these locations reflects what has previously been performed within (internally) the company. As the product cycle progresses, production is moved from the initial agglomeration (metropolis) and spreads to similar location 
in terms of demand conditions. In the standardisation (mature) stage, intense price competition and high demand for low-skilled labour, shift production to locations in the developing countries. Iammarino and McCann (2013) present possible criticism of the nexus between PLC and regional (or urban) analysis. Accordingly, innovation shall not be treated in a simplified way, as being linear. Secondly, internal (firm-level) and external circumstances reach beyond cost activity dimension of multinational firm activity. Especially if one acknowledges many possible "configurations" of MNEs functions (Forsgren, 2008) and motives (Lall and Mohammad, 2007), the specific allocation of a FOE's activity to particular locations is far from being easily predictable.

\subsection{Technological dimension of FDI - a regional point of view}

Both the PLC and internalisation concepts have been criticised by Cantwell (1995), who formulated an international production theory, linked to innovations and technological accumulation. Cantwell extended the theory of FDI to accommodate new elements, related to agglomeration processes and clustering of the economic activity. He also paid attention to a regional dimension of FOEs' activity, as well as to the dynamic aspects of technology and knowledge accumulation that constitute the comparative advantage. According to Cantwell and Piscitello (1999), transnational corporations tend to disperse technological competencies across locations to draw competencies from alternative locations. Locations differ, for instance, in terms of institutional settings. The authors point of view on the changes that happened within the largest MNEs underlines their role as "networkers". Cantwell and Iammarino (2010) assessed the character of linkages of the UK regions with other locations in and outside the UE that are established by the MNEs. The authors proved that there is a conformity between the technological pattern of specialisation of FOEs affiliates and regions' position in the host country "locational hierarchy".

Cantwell and Iammarino (2001) showed the character of interactions between local and global processes. The activity of FOEs in the host countries results in the increased regional inequalities. The "first rank" regions' position is improved, while the less attractive (less competitive) regions are marginalised. The activity of MNEs creates chances that can be utilised by host country regions (by their firms). It implies, for instance, a possibility to cooperate and to become a part of international production (or value-added) networks. Regions with the most advanced technological profiles are able to become part of the technological cooperation networks. Spillover effects stemming from the activity of the FOEs are determined by the character of the host region, its technological position and industrial structure. Processes of technology accumulation by FOEs - propellered by cumulative causation - lead to increased regional inequalities. Moreover, as stipulated by Cantwell, they are limited to the concrete, competitive locations. 
If the technological dimension of FOEs activity is taken into account together with the regional context, a region can be a part of a global network in which skills and competencies are exchanged. It shows that competencies originating from a particular location - through FOEs operations and coordination - can be used in other places. The combination of a region's characteristics with a FOE's ones gives a large number of idiosyncratic interactions that are dynamic. These interactions shall be perceived as having a location-specific context. We do not refer to the gravity concept here (please refer to section 8), and NEG (sections 1.14 and 2.3).

\subsection{NEG - an integrating theoretical concept}

As regards the interpretations of the relations between the global and regional economies, much help comes from NEG, which synthesises location theory with international trade theory into a comprehensive, universal analytical tool (Cieślik, 2005, p. 124). NEG perfectly suits the analysis of foreign trade performed at the regional level, as it tackles the mechanics of agglomeration processes. It is particularly useful for the interpretations of the agglomeration of exporters and exports (in terms of volume) in the metropolitan areas and in the regions located close to the most important export markets (due to lower trade costs). Venables and Krugman's (1990) reference to NEG has shown the consequences of the establishment of the EU internal market for the reallocations of economic activity in the EU. The concentration in the core regions has deteriorated the position of the peripheral regions, from which many firms were "washed back". Brakman, Garretsen, Gorter, van der Horst, and Schramm (2005) show the risk for the peripheral regions to hold on to the economic activity. Moreover, large infrastructural projects financed by the EU structural funds can have an adverse impact on peripheral regions, as they can be more easily serviced from the core ones. Krugman and Elizondo (1996) for Mexico and Tomiura (2003) for Japan show an interesting effect of dispersion of economic activity due to increasing imports, in a situation of initially highly regionally concentrated industrial structure. The increasing import penetration alters the already existing cooperative links and leads to spatial de-concentration of economic activity. The above-given examples of the empirical research show how difficult it is to predict the actual trends in the distribution of the economic activity and foreign trade (Gil, Llorca, and Serrano, 2008) in space. Much criticism has been formulated against NEG by geographers (Martin, 1999a).

Over the years, the NEG has evolved and shifted from the macro-heterogeneity (Ottaviano, 2011) of locations, to micro-heterogeneity of firms, once the Melitz heterogeneity concept has become the fundament for the international trade analysis. An example of empirical research is provided by Forslid and Okubo (2018) for the 49 Japanese prefectures, who have inquired the trade liberalisation effects, showing the concentration of the most productive multiproduct firms in the large markets. The 
frontiers of NEG have been presented by Fujita and Mori (2005), one of the theoretical frontiers being multi-unit firms and spatial fragmentation (Fujita and Gokan, 2005; Fujita and Thisse, 2006).

The evolution of NEG into new-NEG that embraces more of the micro-heterogeneous aspects related to firms' performance shows how complex relations between the region and the global economy are. They are determined by the agglomeration forces, changing trade costs and last but not least by firms' productivity. Trade activity that we focus on is not the only, but definitely the most important channel that links the regional and global economies. Trade activity is the one in which regional and firms' heterogeneities meet, which makes the region's exports worth a serious inquiry. In the above paragraphs, NEG has only been signalled. It is interpreted in a thorough way in part 2.3. 